\title{
The Effect of Hostile Work Environment on Organizational Alienation: The Mediation Role of the Relationship between the Leader and Followers
}

\author{
Ali Abdulhasan Abbas ${ }^{1}$, Adel Abbas Abd Hussein ${ }^{2} \&$ Hussein Huraija Khali ${ }^{3}$ \\ ${ }^{1}$ Department of Accounting, College of Administration and Economics, Karbala University, Iraq \\ ${ }^{2}$ Department of Banking and Finance, College of Administration and Economics, Karbala University, Iraq \\ ${ }^{3}$ Department of Management, College of Administration and Economics, Karbala University, Iraq \\ Correspondence: Ali Abdulhasan Abbas, Department of Accounting, College of Administration and Economics, \\ Karbala University, Iraq. Tel: 964-780-112-7885. E-mail: Fuhrer313@gmail.com
}

Received: December 4, 2016

Accepted: December 21, 2016

Online Published: January 19, 2017

doi:10.5539/ass.v13n2p140

URL: http://dx.doi.org/10.5539/ass.v13n2p140

An analytical research study based on the views of a sample of leaders and followers in the general co. for cars manufacturing in Babylon\Iraq

\begin{abstract}
The present research aims to identify the mediation role of the relationship between the leader and followers in the context of the effect of hostile work environment on organizational alienation. To achieve this, the following scales were adopted: (Calantone \& Benedetto, 1994) scale to measure the variable of hostile work environment: (Payne, 2015) scale to measure the variable of the relationship between the leader and followers; and (Kakabadse, 1986) scale to measure the variable of organizational alienation. The general co. for cars manufacturing was chosen as the field of research, and the survey questionnaire was administered to (436) individuals that comprised of (116) leaders and (320) followers. The confirmative factorial analysis (structural equation modeling) was applied as the next step, using certain descriptive statistics, correlation analysis, simple regression analysis and hierarchal regression analysis based on the mediation variable test of (Baron \& Kenny, 1986). A number of conclusions have been formed, the most important of which are as follows: the hostile work environment variable has a passive effect on the relationship between the leader and followers; the variable of the relationship between the leader and the followers has a passive effect on organizational alienation; and the variable of the relationship between the leader and the followers partially mediates the relationship between the hostile work environment and organizational alienation.
\end{abstract}

Keywords: hostile work environment, the relationship between the leader and followers, the organizational alienation

\section{Introduction}

Currently, business organizations are confronted with several challenges and threats related to both the external and internal environment. The growing effect of these phenomena has led to the evolution of a hostile work environment characterized by a number of passive behaviors such as the lack of functional security, imbalanced work and family lives, ill treatment or harassment at work, bad psychological environment represented by work-related stress, administration's autocratic treatment, conflicts, and employees' exposure to threats $\mathrm{i}$ including all kinds of harassment (Alterman et al., 2013, pp. 666-667). Several other studies expressed anxiety on increased hostile behaviors in work environment like conflicts and violence among employees or among employees and visitors to the organization. The frustration and bitterness manifests in various forms such as impoliteness or physical violence, cursing, constant criticism, insulting statements, threat of harm, noncooperation and concealment of information, all of which make the work environment hard, hinder performance, and result in decreasing communication and failure of team work (Huchinson \& Jackson, 2013, pp. 1-2). The term (hostile work environment) first appeared in the instructive material issued by the committee of equivalent work opportunities in 1980, which stated that employees have the right to work in an environment 
void of hostility irrespective of whether there was an economic effect on the employee or not. In 1994, President Johnson issued a law of civil rights regarding employment, which holds that the discrimination by employers, on account of race, color, religion, gender and national origin, is illegal (Wagner \& Lip, 2005, p. 1).

Thus, the spread of a hostile work environment within the organization makes the employees feel isolation and lack for participation in organizational decision-making, which reflect the sense of disappointment and inability to meet vocational criteria. This, in turn, leads to a sense of dissatisfaction about social relationships with the leaders and workmates, which is also known as organizational alienation. Alienation might also extend to other aspects of organizational life and hence an organization that cannot meet the expectations of decision-making and communications among its employees would be weakened (Aiken \& Hage, 1966, pp. 497-499).

Organizational alienation, in most cases, is a direct consequence of the structural circumstances i.e. (centralization of decision-making, official rules, policies and procedures) that are dominated by bureaucracy. Alienation results from social structures that dismantle work into controllable, separated units that restrict individual independence and decision-making such that an individual is unable to exercise control on work activities and employees feel helpless, ineffective and estranged (Tanewski et al., 2002). Here, a strong and positive relationship between the leader and followers could be relied on and could partially mediate in minimizing the effects of hostile work environment on organizational alienation. This is based upon the condition that the close relationship between the leader and followers and mutual confidence between the two parties might increase leaders' influence, mutual sharing of confidential information, quick response by followers and the possibility of executing plans and targets jointly (Thomas et al., 2013, pp. 64-67). Good relationship between the leader and followers could also promote the growth of self-awareness and expertise for both parties. The existence of a strong relationship between the leader and the followers contributes to self-knowledge, balanced handling of information, transparency of communications and self-verification. These dynamic exchanges in turn help to generate high levels of confidence, support and loyalty among the individuals (Hinojosa et al., 2014, pp. 4-5).

Based on the above observations, the present research aims to identify the mediation role of the relationship between the leader and followers in minimizing the effect of hostile work environment on organizational alienation. The research was carried out at the level of a random sample of leaders and followers in the general co. for cars manufacturing in Babylon Iraq.

\section{Research Questions}

Research inquiries were identified in the light of the logical relationships as field variables depending on the existence of a hostile work environment and passive atmosphere that increase organizational alienation among employees. The inquiries were as follows:

a) To what extent does the hostile environment weaken the strength of relationship between the leader and followers?

b) To what extent does the passive relationship between the leader and followers lead to increased organizational alienation?

c) To what extent does the hostile environment contribute to increased organizational alienation among employees?

d) To what extent does the relationship between the leader and followers mitigate the hostile environment's effect on organizational alienation among employees?

\section{Research Objectives}

The research attempts to achieve a number of basic objectives as follows:

a) Describe and diagnose the level of hostile environment in the general co. for cars manufacturing in Babylon Iraq.

b) Identify the level of the strength of field relationship between the leader and followers.

c) Diagnose the level of organizational alienation at field and analyze its reasons.

d) Test the effect of the hostile environment on the relationship between the leader and followers at the level of the research sample.

e) Test the effect of the relationship between the leader and followers on organizational alienation among employees.

f) Identify the direct and indirect effects of hostile environment on organizational alienation based on the 
relationship between the leader and followers.

\section{Theoretical Background}

\subsection{Hostile Work Environment}

A hostile work environment is characterized by chaos and inability to organize rules intelligibly due to the spread of wrong and disastrous concepts or abnormal interpretations and exposing employees' to danger (Foulds, 1964, 64). Discrimination on the basis of race is considered a part of the hostile work environment and causes damages to the work environment (Jr, 2001, p. 22). Variables related to hostile work environment causing economic losses to the organization include sexual harassment, harassment based on race, national origin, color and religion, child labor, illegal work practices, physical threats, insults, and aggressive nature of speech. (Cass et al. 2010, 303-306). These create a work environment that involves anxiety, nervous collapse, exhaustion, poor self-esteem, hostility, and offence, all of which affect the psychological well-being of employees. In addition, the US courts are witnessing escalating issues of a hostile work environment over the last twenty years that has been represented by harassment in workplace targeting women in particular and discrimination on the bases of religion, nationality and race (Mann \& Goodman, 2008, pp. 191-192). In this context, (Wiener et al., 1995, p. 264) have also pointed that speech or physical behavior of sexual nature, and discrimination on the bases of religion, nationality and race are included within the framework of hostile work environment.

El-Sherif $(2012,2$, p. 11) found through a survey on work environment that impoliteness at workplace is closely related to a hostile work environment and has a passive effect on organizational productivity. The results of the survey were structured based on three distinctive questions:

1) How does impoliteness, or barefaced rude conduct, manifest and how do people interact at the vertical and horizontal level?

2) How do employees tolerate impoliteness? This needs to be considered against a setting of reasons such as fear of losing the job and fear of social rejection .

3) How should leaders identify the types of impoliteness that occurs in the work environment in order to prevent passive impact on organizational performance?

Managers are responsible for drawing up the policies and procedures that can provide clear guidelines for acceptable behavior in the workplace on the bases of organizational, societal and cultural characteristics. (Negles, 2001, pp. 715-717) maintains that a hostile work environment had a profound effect on the labor law, and points out that many lawsuits in the USA have cited the ambivalence of many terms and definitions that can be differently interpreted. Employers and employees have started to realize that their actions subject them to liability, which in turn has led to increased awareness on work relationships and compliance with laws. The Congress has also acknowledged the existence of workplace inequality centered round a bias against the disabled. (Elbanna \& Alhawarai, 2012, p. 7) added that a hostile work environment is one of the most important features for interpreting strategic behaviors and their results although there aren't many studies that have examined the effect of a hostile environment on organizational strategies, structures, decision-making and production.(Psaila \& Birch, 2015, p. 1) stated that anger is an emotional state with the intensity ranging between feeble agitation to rage accompanied with psychological and physiological reactions. Anger forms as a reaction to external events that are viewed as a threat, or as a reaction to frustration and conflict. (Admin, 2012, p. 234) added that the law requires that an employee exposed to hostility in the work environment should prove that he had been exposed to hostile behavior and that he was tough enough or that he had changed work circumstances and created the hostile work environment. (Judge et al., 2006, p. 12) showed that hostility or anger is a reaction to an event or a sequence of special events, that reactions and emotional conducts affect individuals' role in events, that emotional qualities influence the area to be more or less intensive during fits of anger, and that passivity increases the individual's likelihood of receiving unfair treatment by leaders.

Calantone and Benedetto (1994, p. 18) are of the view that a hostile environment likely emerges from increased intensity of prices, products, technological competition, organizational restrictions or insufficiency of resources and passive demographic trends. It is difficult to take a strategic decision in a hostile work environment that cannot be predicted, as it is too difficult to perceive or evaluate any change when the organization is seized by a hostile environment. The authors also suggested that environmental instability of an organization arouses doubts in the potential technological change, demand by customers or competitive strategies. The study also cautioned that this ambiguity causes fluctuations or instability in resources such that it poses difficulties for the organization in protecting its position in the market and renders it unable to adapt to changes. Consequently, the organization is unable to make the right strategic decisions, and the management reaches a state of uncertainty in 
choosing the right strategy towards risk mitigation and innovation. Oyarce $(2009$, p. 27) believes that a hostile environment is the result of the chaos faced by the organization, and that the organization is required to adapt and acclimatize with these unanticipated future threats. The environment can be viewed as the surrounding circumstances, or the forces that execute or regulate the whole social and cultural conditions such as traditions, laws, religion, economy and political organization that affect the individual's life; high levels of competition and uncertainty are considered classic features of hostility in these types of environment.

Davis (2013, p. 2) mentioned another basic element that contributes to a hostile work environment: the exposure of an individual to annoyance in behavior on account of being the member of a protected group like race. The behavior is undesirable, intense or raged to the extent that an employee thinks that this behavior has made his work environment hostile and that any other reasonable person would find this environment to be hostile or harmful to him. Davis $(2013$, p. 2) also pointed out that annoying behavior might take different forms like using insulting remarks and gestures, images and drawings that might hurt a certain group; comments on the physical features of the individual; degrading his ability and status; asking for personal material such as diaries, e-mails or images; or making sexual gestures such as touching the body in an inappropriate manner. The employers would typically claim that the undesired behavior was initially a jovial exchange and that the victim was actively involved at the beginning; thus the law enforcement agencies are often faced with the additional task of verifying whether the victim was, in any manner, one of the participators. Rubin $(1995$, p. 22) mentions several laws issued in the USA that specify the conducts that are considered hostile within the work environment. These laws clearly state that harassment was considered an act of workplace hostility whether it was in the form of insulting remarks, sexual innuendo, or apparent sexual offence. Hostile environment is mentioned in chapter seven of the US law as it leads to actions involving anxiety, hostility and offense.

\subsection{Leader-Followers Relationship}

The theory of leader-followers relationship focuses the unique relationships formed between leaders and followers through a series of exchanges related to work. The relations extend beyond what is required according to the employment contract and are represented by exchange of resources. Leader-followers relationship includes four dimensions: influence represented by admiration and inclination towards people of expertise; loyalty represented by public support; contribution or in other words the psychological willingness to contribute in mutual objectives; and respect for career that includes efficiency, related skills and knowledge. (Wisse \& Rietzschel, 2014, p. 251) added that a positive leader-followers relationship has a constructive effect on employees' satisfaction, organizational commitment, functional loyalty, organizational citizenship behavior and innovation. Personal traits of the leader could also have a direct effect on followers as they are subjected to constant censorship by followers. Further, technological changes play a considerable role in increasing collaboration between the leader and followers. Political changes also affect the behavior of leaders and how they treat their followers; lack of confidence in the organization increases the gap between the leader and followers and generates ideological conflict (Gariza, 2011, pp. 697-699).

Relationships between the supervisors and subordinates develops based on a series of interchanges related to work that range from direct limited interchanges related to the work contract to exchange of resources that extends beyond what is required by the work contract (Wisse \& Rietzschel, 2014, p. 251). The leader-followers relationship involves a number of features such as the followers obeying the leader unconditionally, giving the leader emotional support and trusting his declarations (Post, 1986, p. 676). Unless there is balance between the authority and followers, the psychological health of followers would be undermined by the demands made on them, and when a conflict emerges it would spread in many directions. The authors also added that sometimes the followers view the leader as a means to seize power and that many of the followers abandon some aspects of themselves in order to hold on to power. This behavior is explained in the literature of self-psychology but finally it is self-destructive, forms deep roots, and puts the original-self at risk. Fears and passive feelings in the leader might pass into followers if he couldn't conceal them (Dumas \& Sankowsky, 1998, p. 32).

Winkler (2011, p. 504) defined the leader-followers relationship as the process of interaction between the leader, the followers and the positions that are based on the exchange of dynamic relationships; the authors noted that leader-followers relationship develop interchangeably. Many studies have shown that healthy leader-follower relationships lead to increasing functional satisfaction, reduced average of employees' rotation, more positive evaluation of performance and high degree of participation. Gardner et al. (1987, p. 279) stated that among the factors that affect leader-followers relationship are the characteristics of the work environment itself that have an impact on the employees while they are at work. Boy and Tylor $(1998$, p. 2) maintain that interchangeable relationships between the leader and followers are founded on the qualities of work relationship rather than personal relationships or friendship and that it consists of a number of dimensions like: respect, confidence and 
reciprocal commitment. Lim and Chidambaram $(2011$, p. 2) also stated that the official leadership might not be able to gain respect to the extent possible in leader-followers relationships.

Stephenson (2011, p. 186) further said that leader-followers relationship would be better if an atmosphere of agreement prevailed among them; the parties would not be willing to share information, consult with each other, or be open to new ideas unless there is confidence between the leader and followers. On the other hand, if the leaders were perceived as bad, an atmosphere of rejection and disagreement would prevail. (Martinez et al., 2012, p. 143) believe that there is a dynamic relationship between the leader and followers that plays a fundamental role in the organization and the concept of power that stems from the idea that individual $\mathrm{A}$ is more powerful than individual B in that individual B relies on individual A for resources necessary to meet his needs, desires and objectives.

Coyli and Foti (2014, p. 12) concluded that low-quality relationships between the leader and followers penetrate into the workforce and might directly impact profits, revenues and other financial parameters. Grayson and Speckhart (2006, p. 3) confirmed that leader-followers relationship are inseparably overlapped concepts. In fact Japanese work schools deal with the concept of leader-followers relationship as two integrated aspects; the leader should provide directions within the range of objectivity, anticipations, limits and principles of guidance while the followers should raise questions to guarantee understanding and contribute to the definition of the project.

Savolainen (2009, p. 1) stated that confidence in leadership is the base for communication and cooperation between the leader and followers, while (Gardner et al., 1987, p. 279) believe that strong focus on supervision consolidates the leader-followers relationship and the followers' response to the leader in work as well as the qualities of the work environment that affect employees while at work. (Kark, 2011, 429-430) further said that many theories of leadership have concentrated on the importance of leader-followers relationship with focus on equality, cooperation and recognizing the significance of relationships in consolidating positive personal and organizational outcomes. Leadership at the level of exchange and distribution is confined to a single person; however, it is also a social process and human interactions are what intensify the intimate relationship between the leader and followers. (Pelletier, 2012, 419) emphasized that unhealthy leadership has a poisonous effect on the leader-followers relationship and would affect the social identity of work groups as well as followers' perceptions towards the leader; the followers might confront the leader if he was targeting an individual within a community or challenge him if they were members of a community. (Malakyan, 2014, 18) thinks that leader-followers relationship can influence the process of decision-making alternatively and harmoniously. We may expect that the leader-followers relationship in the workplace will be based on personal preferences, points of strength, competence experiences, and increase in the organization's productivity.

Neinaber (2014, p. 18) suggested that developing emotional confidence in the first place depends on leader-follower interaction where positive anticipations are closely related to cognitive confidence; this means that confidence between the leader and followers is of economic costs as well. Adair $(2015$, p. 7$)$ added that the behaviors that strengthen confidence in leader-followers relationships stem from constant fair treatment and promote balance between life, home and work; if the leader is unable to understand the equation between work and home, he would be unable to handle the critical issues confronted by employees. Payne (2015, p. 19) on the other hand, emphasized that followers who have a positive relationship with the leader are the ones who participate more and are more willing to assume a positive role within the organization. The leader has to strengthen such efforts to take initiative and mentor such employees as future leaders, so as to stimulate innovation and enable the organization to survive even in the most disturbing economic circumstances.

\subsection{Organizational Alienation}

Researchers have recognized that organizational alienation stands at the meeting point between circumstances of social structure and psychological adjustment, and that alienation consists of two dimensions, weakness and self-estrangement. Employees' weakness/strength consists of the parameters of autonomy in job and functional confidence, while alienation refers to skepticism towards authority and hostility among individuals. Weakness reflects a feeling of inadequate autonomy in performing daily duties and tasks, while the confidence parameter represents the feeling of disappointment with the job, career development and inability to meet career criteria. Self-estrangement refers to the degree of dependence on a standard behavior on the basis of the expected future rewards that are off the activity itself; here the person considers himself a foreigner, i.e. the person runs away from himself, something that could be taken as a parameter in questioning the authority. Hostility among people refers to the degree of incoherence among workmates bound to a hierarchical order (Kakabadse, 1986, 458-461). Alienation is a feeling of helplessness, weakness, and social isolation where employees have low levels of 
self-confidence which in turn poses many difficulties in meeting their needs. They also feel a sense of deprivation which might result in functional dissatisfaction and therefore unwillingness to participate in work. Meeting the needs of the individual via his organizational membership requires a high level of energy and efforts, as well as constant orientation to achieving organizational objectives. Feelings of helplessness, weakness and alienation might interfere with the work potentials of the alienated employees and hinder the achievement of organizational objectives; thus self-confidence levels of the aliened employees as well as their levels of performance would be low(Efraty et al., 1991, pp. 60-61).

(Sirin \& Sirin, 2013, 177) defined organizational alienation as a hindrance that affects the environment and the community the individuals associate to within their job. In other words, when individuals engage in their work without initiative for a long time, it makes them desperate for having a great effect on their work outcomes and at this point they start to doubt the system around them. Individuals who construct evaluative rules based on their previous experiences start to ignore the system's rules, lose control on daily functional tasks and are unable enough to express themselves at the workplace. (Shehada \& Khafaji, 2015, 83-84) pointed out that organizational alienation includes multiple manifestations. According to (Lufthansa, 1973), some forms are :

1) Helplessness: the employee loses his freedom and the central authority has no mercy.

2) Uselessness: the employee feels that all the works and activities are worthless, that there is a conspiracy, and that he is being treated unfairly.

3) Losing norms and traditions: the employee feels that all the norms and traditions he believed in have been distorted and ignored.

4) Isolation: the employee feels that the organization he works in as well as the society he lives in doesn't appreciate him.

5) Psychological alienation: the employee loses direction and sense of identity, and is convinced that being good is of no avail .

Organizational alienation may result from placing a good employee in an unsuitable place, conflict among employees regarding loyalty, workplace politics, cultural transitions, imported technology, leadership styles, and unjust evaluation of the employees. (Rajaeepour et al., 2012, pp. 189-190) further said that organizational alienation occurs when the activities of the organization become an external affair for the individual i.e. not a part of his nature; he would therefore become dissatisfied about work at the organization, distance himself, feel useless and remain unhappy. His physical and mental activities are characterized by low levels of energy and motivation; he finds himself tired and humiliated, wouldn't work voluntarily, considers it a compulsory activity, and feels unaffiliated to the organization.

(Sulu et al., 2010, p. 29) observed that, in a state of alienation, employees are unable to meet their social needs and perceive a gap between work objectives and some of their interests like values, ideals and desires. Organizational alienation separates the employee from work and the workplace cognitively and manifests in low participation, lack of organizational identity, low level application of skills, fighting and disagreements at workplace, restricted involvement, lack of commitment to organizational objectives, avoidance of responsibility, unsatisfactory levels of autonomy, and lack of interest in realizing profits for the organization. (Pelit et al, 2015, pp. 86-90) thought that among the reasons that contribute to organizational alienation is nepotism involving relatives which will have the effect of demoralizing employees, who are compelled to work with the relatives of executive superiors. This in turn causes damage to organizational relationships, weakened connections among employees and inactivity in the work environment, and might have a passive impact on the level of employees' satisfaction. The authors also added that organizational alienation is an attitude characterized by employees' passivity towards their organizations; it is a state of psycho- social disturbance that involves an attitude of introversion due to unavailability of values and exclusion from social processes which might cause reluctance to participate in organizational life and separation from self-essence. They further attributed three dimensions for organizational alienation which are weakness, uselessness and self-estrangement.

(Yorulmaz et al., p. 32) mentioned that organizational alienation is a multi-dimensional, passive emotional structure that stems from an interface of external factors among individuals, the created products and services. The researchers added that organizational alienation is identified in five sub dimensions as follows :

1) Helplessness: refers to the external factors that are widely spread over individuals' behaviors

2) Uselessness: appears as a result of conflict among individual traits and societal factors .

3) Anomaly of standards: happens when some of the individuals don't reveal the rules behind what is of value to 
the organization.

4) Isolation: means staying away from people in the immediate environment

5) Self-estrangement: rises as a result of unregulated internal conducts of individuals.

(Tummers \& Dulk, 2013, p. 12) pointed out that these different dimensions could have different effects. The dimension of "uselessness", for example, has a greater effect than "helplessness", as the feeling of workplace worth is more important than aspects of strength. (Chen et al., 2012, pp. 4-6) believe that alienation is a deviation of values, behaviors and anticipations among individuals and society. It is the feeling of uselessness and dissatisfaction about the jobs they do and the inability to realize their own organizational identity. The alienated might feel reluctant to adapt to technology as he doesn't understand it quickly, or even feel alienated to computers, bureaucratic restriction, organizational unjustness, autocratic behaviors of superiors, unsuitable methods of management and the complicated system of performance checking. As to organizational outcomes, feelings of alienation prevent the individual from becoming involved in work, limit his organizational commitment, and reduce functional involvement and satisfaction. (Banaai et al., 2004,377) view organizational alienation as a decreasing inclination toward work that prevents him from absorption in work; thus it is both a state of psychological separation from work and a lack of power to meet the most important needs and aspirations of an individual.

(Branneh \& Peterson, 2009, pp. 470-471) point out that organizational alienation refers to emotional and behavioral reactions towards a group of employees represented by alienation as a result of excessive routine and work pressure and unavailability of censorship. It is a kind of psychological separation between the self and work, and four aspects of this complicated state have been identified as follows:

1) Helplessness: lack of control upon the pace and the methods of work, 2) Interruption: lack of understanding of how the work of the individual correlates with organizational processes

3) Social isolation: lack of integration in the work community

4) Self-estrangement: the purpose of work as a means to achieve a goal but not self-realization.

(Valadbigi \& Ghodadi, 2012, p. 75) stated that the development of the production system and the modern production techniques based on huge production imposed work division, machinery and automation and made it appear that factories be far from homes and that the aim of these processes are not to meet individuals' needs but to achieve profits. All this had an important role in the alienation process, separation from production, self-estrangement and alienation from others and society. (Rovai Wighting, 2005, pp. 98-99) suggests that organizational alienation refers to the feeling of social alienation, and absence of social support or meaningful social communication. It often correlates with certain issues such as self-isolation, failure, breakaway from work and feelings of loneliness; the individual feels that nobody cares or pays attention to them. He further said that alienation in the organization consists of three dimensions:

1) Isolation: feeling of loneliness even when the individuals are among others due to the lack of intimate relationships with their peers, family and society at large.

2) Helplessness: feels unable to make choices and believes that one has no control on what happens.

3) Rejection of standards: involves the refusal to be dominated by the rules and values of the society, affecting performance at work.

(Mendoza \& Lara, 2007, pp. 58-59) further said that alienation represents a contradiction between the individual's tendencies and the requirements of reality; it involves apathy towards workplace which takes the form of a gap between the perceived objectives of work and the individuals' interests. They also pointed out a number of dimensions of organizational alienation as follows: helplessness, uselessness, anomaly of standards, isolation, and self-estrangement .

(Rauf, 2015, pp. 95-96) suggested that the most important dimensions of alienation in the organization are feelings of helplessness and uselessness that are passively correlated with organizational commitment and hard work. He also pointed out that in a work environment characterized with alienation and insufficient control over taking decisions, individuals feel that resources are distributed unjustly and that the organization's objectives wouldn't be achieved adequately. This in turn would inhibit behaviors of organizational citizenship and make employees reluctant to participate in work, leading to decreased functional satisfaction.

(Valikhani \& Soltani, 2015, p. 279) are of the view that alienation involves a feeling of inability and self-conceit and that the employee is dissatisfied with the work he is doing. (Shantz et al., 2015, p. 2) thinks that organizations characterized with significant alienation make the employee consider work as merely a means for 
survival rather than self-realization; in such a workplace, the employee would not get personal relief from work. (Cox \& Wood, 1980, p. 3) stated that the bureaucratic system increases resentment and conflict over the control of organizational and vocational structure which intensifies alienation among the employees in the organization. (Ramaswami et al., 1993, p. 180) believe that alienation of the employee increases when his job isn't freely chosen and the work environment does not offer opportunities to express his potentials and suggestions, so his motivation is low and he won't invest all of his skills and abilities . (Thomas \& Zingraff, 1976, p. 103) added that an organizational structure that consolidates the levels of general alienation leads to apathy toward the society. (Podsakoff et al., 1986, p. 820) concluded, through their research, that the indirect effects are represented by ambiguity and conflicts over the role, and an organizational identity that plays a role in increasing alienation. The researchers also found that applying a formal atmosphere in the organization has a poor effect on limiting organizational alienation.

(Korkmaz \& Aydemir, 2015, pp. 233-234) are of the view that the concept of alienation appeared for the first time in Phenomenology of Spirit by (Hegel, 1807). Alienation in the organization is defined as a psycho-sociological disease created as a result of introversive attitudes due to the absence of values, inability of the individual to participate in productive processes, individual's feeling of isolation and abandonment of his environment and work, work and personality traits that limit the individual's adaptation to social and cultural life and an unfamiliar environment; it is characterized with a sense of weakness, uselessness, lack of organizing, social alienation and self-isolation. Among the factors that cause alienation in the organization are: management methods, past events and experiences, size of the organization (field of checking, authority transition, specialized officials, centralization and decentralization), information outflow, group qualities (social structures and their role in groups, rules and standards, cooperation among groups, leadership in groups), intensity of relationships (polite, superficial, temporal), type of manufacturing (unit, serial, continual, customized manufacturing), work division, work conditions (noise, high pace of work, exertion, boredom, monotony, isolation, working hours in one place, participation and human relationships), beliefs and attitudes. He also pointed out certain environmental factors that lead to alienation such as: (economic, technological, social, cultural, political and legal structures) in addition to manufacturing, urbanization, social rupture, union centers and mass media. (Allen \& Lafollette, 1977,334) further said that alienation is a widespread social phenomenon that is directly related to certain sectors of society.

\section{Research Hypotheses}

The present research includes three major hypotheses as follows:

a) The first main hypothesis: there is a significant reverse effect of the hostile environment in the leader-followers relationship

b) The second main hypothesis: there is a significant reverse effect of the leader-followers relationship in organizational alienation

c) The third main hypothesis: 1. there is a significant direct effect of the hostile environment in organizational alienation 2. there is a significant indirect effect of the hostile environment in organizational alienation through leader-followers relationship.

\section{Research Plan}

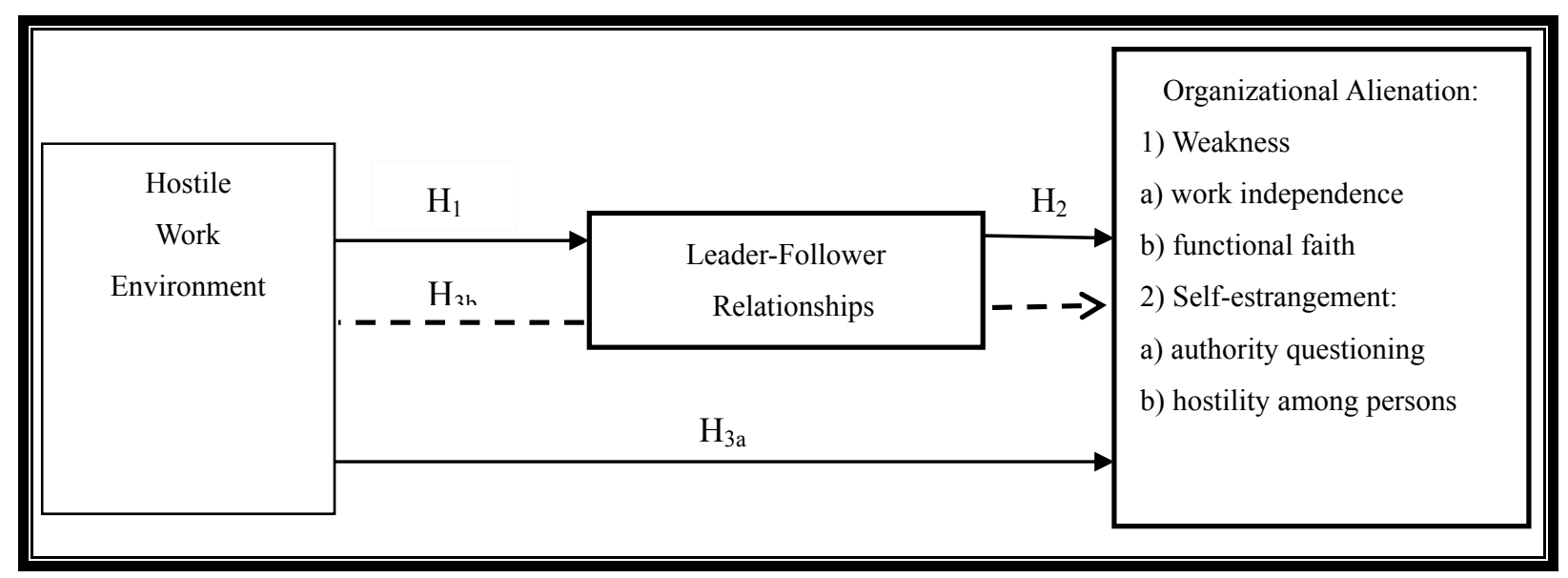

Figure 1. Research Hypothetical Diagram 
The hypothesis diagram shows all the perceptions that connect the research variables and the direction of these relationships from the influential variables to the affected ones directly and indirectly as shown in Figure (1) Research hypothetical diagram.

\section{Research Methodology}

\subsection{Research Measures}

The research includes three basic variables as follows:

1) Hostile work environment: represents the dependent variable of the research as (Calantone \& Benedetto, 1994) scales has been adopted in measuring this variable which is a one-dimensional variable measured by (6) items

2) Leader-followers relationship: represents the mediation variable of the research as (Payne, 2015) scale has been adopted in measuring this variable which is a one-dimensional variable measured by (7) items

3) Organizational alienation: represents the adopted variable of the research as (Kakabadse, 1986) scale has been adopted to measure this variable which consists of four sub variables: work independence (3) items, career achievement (5) items, Questioning authority (3) items, and hostility among individuals (5) items as shown in Table (1). Likert's Penta scale has been adopted to identify answer's alternatives on the items of this variable which includes five grades as follows:

(I don't totally agree 1, I don't agree 2, neutral 3, I agree 4, I totally agree 5)

Table 1. Table Research variables and scales

\begin{tabular}{cccc}
\hline $\mathbf{N}$ & Variable & Scale & Number of paragraphs \\
\hline 1 & HWE & Calantone \& Benedetto, 1994 & $\mathbf{7}$ \\
\hline 2 & LFR & Payne, 2015 & $\mathbf{7}$ \\
\hline 3 & OA & Kakabadse, 1986 & $\mathbf{1 6}$ \\
\hline
\end{tabular}

\subsection{Research Sample}

The general co. for cars manufacturing located in Babylon Iskandariya has been chosen to be the place where the research was applied. Data have been collected by choosing a sample consists of leaders and followers from administrative departments, technicians, employees in production departments, workshops, different plants of the company such as (buses, lorries, bodies and trailers, after-sale services and saloon cars plants). Questionnaire forms were distributed through interviews with the research subjects in their places of work and the items of the questionnaire were explained, the practical concepts of the items and answering whatever questions on how to reply them. (500) questionnaire forms were distributed on participants, (436) of them were suitable for statistical analysis and the percentage of the taken back forms was $87 \%$. Unsuitable forms of questionnaire and those of incomplete or incorrect answers were neglected. The sample consisted of (116) leaders and (320) followers from different plants and departments of the company.

\subsection{Demographic Qualities of Subjects}

Research sample consisted of $(81 \%)$ males and $(19 \%)$ females, as it suits the field nature of industrial and productive work of the company. Participants percentage was (25\%) for ages less than (35), (52\%) ranged from (35 to 45$)$ years and (23\%) aged older than (46). As for scientific qualification of participants, High school (25\%), Diploma (28\%), Bachelor degree (40\%), Master degree (7\%). Functional experience in work of participants was (43\%) for those who have service on job from (1-10) years, (34\%) for (11-20) years of service and $(23 \%)$ for more than (21) years of service. As to functional position, the percentage of administrators was (31\%), the engineers' was (34\%) and technicians' was (35\%).

\section{Confirmatory Factor Analysis}

To verify the constructive validity of scales, researchers have conducted confirmatory factor analysis of the scales adopted to verify the validity of the theoretical constructions of variables and their field scrutiny. It is a special state of modeling the structural equation aims at fitting the available hypothetical structure of variables with the data collected on it. Thus, confirming the relation among the dimensions and the items and that the items are not oriented to all dimensions which ensures that each dimension is represented by a clear and suitable number of unobserved items (Albright \& Park, 2009, p. 3). The statistical package (Amos version 21) was adopted in conducting the confirmatory factor analysis. In order to evaluate the structural model resulting from 
confirmatory factor analysis outputs, researchers recommended that the two following standards should be verified: (Schumacker \& Lomax, 2010, p. 169). Parameter Estimates: represent the values of tracks that connect the latent variables with the unobserved variables. When these parameters are evaluated, the feasibility of parameter estimates should be taken into consideration and they should be feasible and accepted if their values exceeded (\%0.40) (Holtzman \& Sailesh, 2011, p. 13) and (Model Fit Index's) establish the norm whereby judging the extent and scrutiny of fitting the resulted structural model. Table (2) shows the most important fitting indices adopted in confirmatory factor analysis.

Table 2. Table indexes of structural model fitting according to (Amos V.21) outputs

\begin{tabular}{|c|c|c|}
\hline No. & Type of index & The extent of value and acceptance rule \\
\hline 1. & $\begin{array}{l}\text { The ratio between the value of }\left(\chi^{2}\right) \text { and degrees } \\
\text { of freedom }(\mathrm{CMIN} / \mathrm{df})\end{array}$ & $\begin{array}{c}\text { Less than }(0.05) \text { good, less than }(0.02) \text { fit, higher than }(0.05) \\
\text { refused }\end{array}$ \\
\hline 2. & The Goodness-of-Fit Index (GFI) & $\begin{array}{l}\text { The extent of value between }(0-1) \text {, acceptance rule is more than } \\
\qquad(0.90)\end{array}$ \\
\hline 3. & The Normed Fit Index (NFI) & $\begin{array}{l}\text { The extent of value between }(0-1) \text {, acceptance rule is more than } \\
\qquad(0.90) \text { more than }(0.95) \text { fit }\end{array}$ \\
\hline 4 & The Comparative Fit Index (CFI) & \\
\hline 5 & The Relative Fit Index (RFI) & Over the value of $(0-1)$, acceptance base of more than $(0.90)$ more \\
\hline 6 & The Incremental Fit Index (IFI) & than $\left(\begin{array}{ll}0 & 05\end{array}\right)$ \\
\hline 7 & The Tucker-Lewis Index (TLI) & \\
\hline 8 & The Root Mean Square Error of Approximation & $\begin{array}{c}\text { Less than }(0.05) \text { fit, values }(0.05-0.08) \text { good, values }(0.08-0.10) \\
\text { moderate, values more than }(0.10) \text { refused }\end{array}$ \\
\hline
\end{tabular}

Based on the aforementioned, the results of confirmatory factor analysis of variables were as follows:

\subsection{Hostile Work Environment Scale}

Figure (2) shows that hostile environment variable is measured by (6) items, when (Standard Parameter Estimates) were reviewed, we found that they have exceeded (0.40) which are visible on the arrows that connect variables with their items. This proves the validity and feasibility of parameters. As for model fitting indices, findings showed that all of which meet their own rule of acceptance with the values shown in (Table 3). Therefore, the structural model has attained a high level of fitting. Which confirms that the hostile environment variable is unilateral variable dimension is measured with (6) paragraphs interconnected.

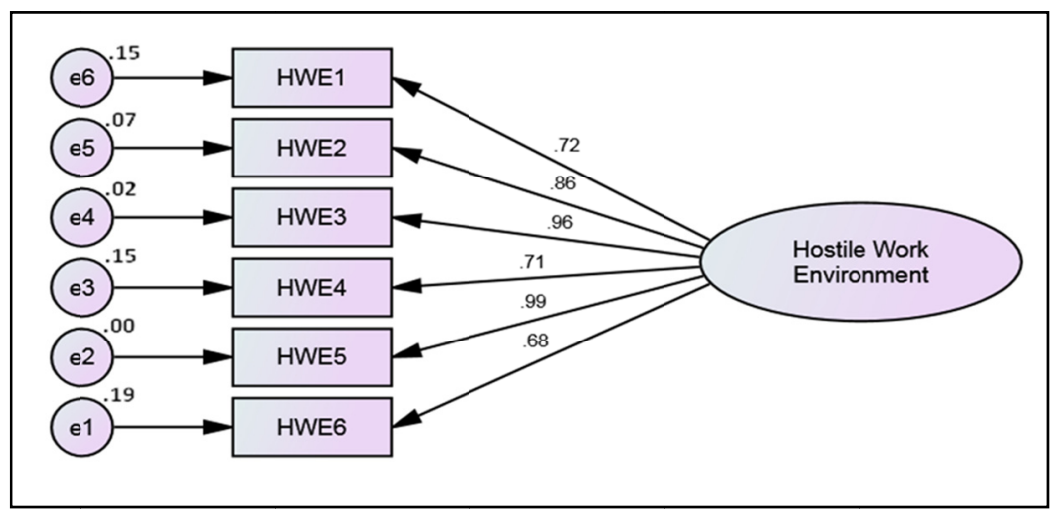

Figure 2. Figure Confirmatory factor analysis of hostile work environment

Table 3. Table Indexes of Structural Model Fitting of hostile environment scale

\begin{tabular}{cccc}
\hline Index & Value & Index & Value \\
\hline CIMN/df & 10.062 & GFI & 0.903 \\
NFI & 0.950 & CFI & 0.955 \\
RFI & 0.907 & IFI & 0.955 \\
TLI & 0.915 & RMSEA & 0.024 \\
\hline
\end{tabular}




\subsection{Leader-Followers Relationship Scale}

Figure (3) shows that Leader-followers relationship variable is a one-dimensional variable measured by (7) items, when (Standard Parameter Estimates) were reviewed, it was found that they have exceeded $(0.40)$ which are visible on the arrows that connect variables with their items. This proves the validity and feasibility of parameters. As for model fitting indices, findings showed that all of which meet their own rule of acceptance with the values shown in (Table 4). Therefore, the structural model has attained a high level of fitting and this proves that Leader-followers relationship variable is a one-dimensional variable measured by (7) items.

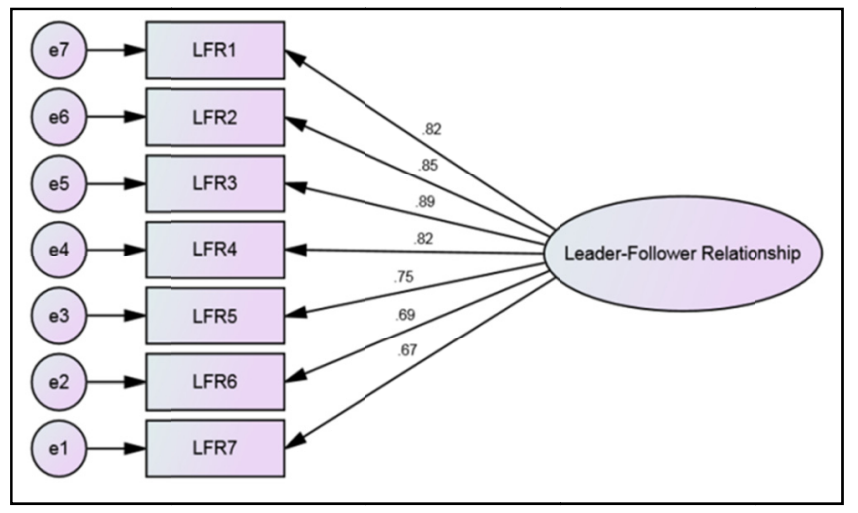

Figure 3. Figure Confirmatory factor analysis of Leader-followers relationship

Table 4. Table Indexes of Structural Model Fitting of Leader-followers relationship scale

\begin{tabular}{cccc}
\hline Index & Value & Index & Value \\
\hline CIMN/df & 4.101 & GFI & 0.937 \\
NFI & 0.944 & CFI & 0.956 \\
RFI & 0.915 & IFI & 0.957 \\
TLI & 0.935 & RMSEA & 0.012 \\
\hline
\end{tabular}

\subsection{Organizational Alienation Scale}

Figure (4) shows that organizational alienation variable includes (4) sub dimensions measured by (16) items, when (Standard Parameter Estimates) were reviewed, it was found that they have exceeded (0.40) which are visible on the arrows that connect variables with their items. This proves the validity and feasibility of parameters. As for model fitting indices, findings showed that all of which meet their own rule of acceptance with the values shown in (Table 5). Therefore, the structural model has attained a high level of fitting and this proves that organizational alienation variable measured by (16) items divided on (4) sub dimensions.

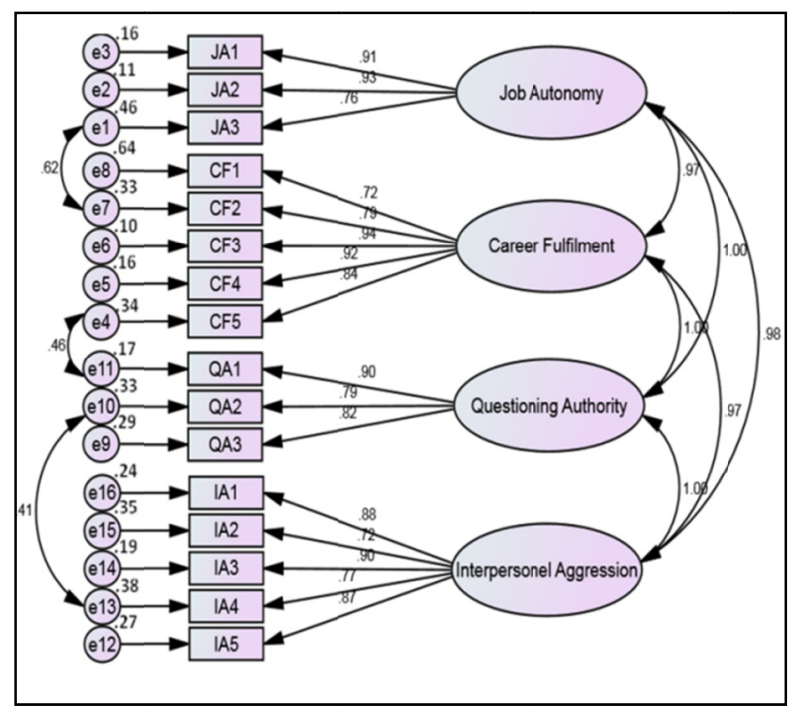

Figure 4. Confirmatory factor analysis of organizational alienation 
Table 5. Table Indices of Structural Model Fitting of organizational alienation scale

\begin{tabular}{cccc}
\hline Index & Value & Index & Value \\
\hline CIMN/df & 3.642 & GFI & 0.928 \\
NFI & 0.941 & CFI & 0.979 \\
RFI & 0.974 & IFI & 0.944 \\
TLI & 0.936 & RMSEA & 0.038 \\
\hline
\end{tabular}

\section{Invariability Coefficient, Descriptive Statistics and Correlations among Variables}

Table (6) shows invariability coefficient values and descriptive statistics (arithmetic mean, standard deviation) of the research variables and correlation coefficients among them as follows:

Table 6. Table descriptive statistics and, reliability coefficient (Cronbach's Alpha) and correlation coefficients among the research variables

\begin{tabular}{lllllllllll}
\hline Var. & $\alpha$ & $\mathrm{M}$ & $\mathrm{SD}$ & 1 & 2 & 3 & 4 & 5 & 6 & 7 \\
\hline 1.HWE & .813 & 3.10 & .354 & 1 & & & & & \\
2.LFR & .803 & 2.79 & .471 & $-.209^{* *}$ & 1 & & & & \\
3.JA & .740 & 3.13 & .411 & $.178^{* *}$ & $-.332^{* *}$ & 1 & & & \\
4.CF & .875 & 2.84 & .559 & $-.169^{*}$ & $.387^{* *}$ & $-.397^{* *}$ & 1 & & \\
5.QA & .792 & 3.07 & .440 & $.264^{* *}$ & $-.152^{*}$ & $.229^{* *}$ & $-.352^{* *}$ & 1 & & \\
6.IA & .776 & 3.16 & .484 & $.195^{* *}$ & $-.166^{*}$ & $.150^{*}$ & $-.178^{* *}$ & .070 & 1 & \\
7.OA & .859 & 3.05 & .308 & $.307^{* *}$ & $-.406^{* *}$ & $.655^{* *}$ & $-.770^{* *}$ & $.612^{* *}$ & $.535^{* *}$ & 1 \\
\hline
\end{tabular}

\subsection{Hostile Work Environment}

Table (6) shows that (Cronbach's Alpha) value of hostile work environment has reached (0.813) which is a good value and can be adopted. This variable has also obtained, to some extent, high arithmetic mean reached (3.10) on the level of subjects' answers, thus it is higher than the hypothetical mean which is (3). As to the extent of homogeneity in answers, it becomes clear via standard deviation which has reached (0.354) i.e. high homogeneity among subjects' views. These findings shows that there is a hostile environment at the internal atmosphere of the general company for cars manufacturing. This might be due to the decrease of factors of commitment, satisfaction, behavior of citizenship, lack for job security, bad treatment, continual teasing in work, high work pressure, decreased confidence factors, little participation, dictatorship in taking decisions, conflicts and other factors.

\subsection{Leader-Followers Relationship}

Table (6) shows that (Cronbach's Alpha) value of Leader-followers relationship variable has reached (0.803), a high value that could be depended upon, while the arithmetic mean has reached (2.79) less than (3) and has got a standard deviation of (0.471). this result proves the weak Leader-followers relationship, weak homogeneity, lack for communication and cooperation in work practicing rather than the fears that might generated to the leader due to enabling them assume their duties and fulfill their commitments whereof leads to the decrease of confidence among them, weak response by followers, delay in the execution of plans and objectives which in turn lead to more conflicts and lack of conformity.

\subsection{Organizational Alienation}

Table (6) shows that (Cronbach's Alpha) value of organizational alienation variable has reached (0.859), a high value that could be depended upon, while the arithmetic mean has reached (3.05) slightly higher than the hypothetical mean (3) and has got a standard deviation of (0.308). this result proves that a high proportion of the research sample feels organizational alienation and practices its functional work under the factors of disability, weakness and social isolation inside the company which might have passive effect on the factors of confidence, feeling of responsibility, participation in work, feeling of worthlessness and weak communication with others and that might lead to functional dissatisfaction. 
As to correlation matrix, it attempts to identify the strength of correlations among the research variables and how could be relied upon in planning the test of effect hypotheses, as it is obvious from table (6) that there are significant correlations among the research variables at the level of significance $(0.01)$ and $(0.05)$ such that confirming the relationship between the variables and how much they are aligned in the environment of the general company for cars manufacturing which in turn enable to field test of the research hypotheses.

\section{Research Hypotheses Test}

This axes deals with the research hypothesis test, simple regression test and hierarchal regression analysis with their statistical parameters which include (F) test, (B) coefficient, $(\mathrm{T})$ test and $\left(\mathrm{R}^{2}\right)$ coefficient have been used down to determining the effect correlations among the research variables as follows:

\subsection{The First Hypothesis Test}

Table (7) shows the results of simple regression analysis outputs to test the effect extent of the hostile work environment on leader-followers relationship at the level of the company under discussion.

Table 7. Table parameters of simple linear regression model of the first hypothesis test

\begin{tabular}{|c|c|c|c|c|c|c|c|}
\hline \multirow{2}{*}{$\begin{array}{l}\text { Independent variable } \\
\text { Dependent variable }\end{array}$} & \multicolumn{4}{|c|}{ Leader-Follower Relationship } & \multirow[t]{2}{*}{$\mathrm{R}^{2}$} & \multirow[t]{2}{*}{$\mathrm{F}$} & \multirow[t]{2}{*}{ Sig. } \\
\hline & Con. & $\beta$ & $\mathrm{t}$ & Sig. & & & \\
\hline Hostile Work Environment & 1.934 & -.209 & -3.136 & .002 & .044 & 9.836 & .002 \\
\hline
\end{tabular}

It is obvious from table (7) that the marginal inclination value of the regression angle (partial regression coefficient Beta) has reached $(B=-0.209)$ which is a significant value because the calculated value $(t)$ which is $(-3.136)$ is a significant value at $(\mathrm{Sig} .=0.002)$ while the value of $\left(\mathrm{R}^{2}\right)$ has reached $(0.044)$ i.e. the hostile work environment explain a proportion of (4.4\%) of the changes that occur to the leader-followers relationship. As to the remaining $(95.6 \%)$, it refers to other variables not included in the research model. Based on the results attained above, there is a significant effect of hostile work environment on the leader-followers relationship.

\subsection{The Second Hypothesis Test}

Table (8) shows the results of simple regression analysis outputs to test the effect extent of the leader-followers relationship on organizational alienation at the level of the company under discussion.

Table 8. Table parameters of simple linear regression model of the second hypothesis test

\begin{tabular}{llllllll}
\hline \multirow{2}{*}{$\begin{array}{l}\text { Independent variable } \\
\text { Dependent variable }\end{array}$} & \multicolumn{3}{l}{ organizational alienation } & \multicolumn{2}{l}{$\mathrm{R}^{2}$} & $\mathrm{~F}$ & \multirow{2}{*}{ Sig. } \\
\cline { 2 - 5 } & $\mathrm{Con}$. & $\beta$ & $\mathrm{t}$ & $\mathrm{Sig}$. & & & \\
\hline leader-followers relationship & 2.313 & -.406 & -6.526 & .000 & .165 & 42.583 & .000 \\
\hline $\mathrm{N}=436$ & & & & & & &
\end{tabular}

It is obvious from table (8) that the marginal inclination value of the regression angle (partial regression coefficient Beta) has reached $(\mathrm{B}=-0.406)$ which is a significant value because the calculated value $(\mathrm{t})$ which is $(-6.526)$ is a significant value at $(\mathrm{Sig} .=0.000)$ while the value of $\left(\mathrm{R}^{2}\right)$ has reached $(0.165)$ i.e. the hostile work environment explain a proportion of $(16.5 \%)$ of the changes that occur to organizational alienation. As to the remaining $(8305 \%)$, it refers to other variables not included in the research model. Based on the results attained above, there is a significant effect of the relationship between the leader-followers relationship on organizational alienation.

\subsection{The Third Hypothesis Test}

The third hypothetical test requires that the mediation role assumed by the leader-followers relationship variable between the hostile environment and organizational alienation be determined. It is essential to adopt the mediation model test established by (Baron \& Kenny, 1986:11731186) that requires using the hierarchal regression analysis for this purpose.

Table (9) shows the results of hierarchal regression analysis. The first model includes the regression analysis of the effect of the independent variable of hostile work environment on the adopted variable of organizational alienation, while the second model has included the regression analysis of the independent variable of hostile environment in addition to the mediation variable of leader-followers relationship on the variable adopted in organizational alienation. 
Table 9. Table parameters of multi-regression model of the third hypothesis test

\begin{tabular}{|c|c|c|c|c|c|c|c|c|}
\hline \multirow{2}{*}{ Model } & \multirow{2}{*}{$\begin{array}{l}\text { Independent variable } \\
\text { Dependent variable }\end{array}$} & \multicolumn{4}{|c|}{ organizational alienation } & \multirow{2}{*}{$\mathrm{R}^{2}$} & \multirow{2}{*}{$\begin{array}{l}\text { Change } \\
\mathrm{R}^{2}\end{array}$} & \multirow{2}{*}{ Sig. } \\
\hline & & Con. & $\beta$ & $\mathrm{t}$ & Sig. & & & \\
\hline First & HWE & 2.227 & .307 & 4.737 & .000 & .094 & -- & 22.443 \\
\hline Second & $\begin{array}{l}\text { HWE } \\
\text { LFR }\end{array}$ & 1.775 & $\begin{array}{l}.232 \\
.357\end{array}$ & $\begin{array}{l}3.761 \\
5.788\end{array}$ & $\begin{array}{l}.000 \\
.000\end{array}$ & .216 & .122 & 33.503 \\
\hline
\end{tabular}

It is obvious from table (9) in the first regression model, that value of the (partial regression coefficient Beta) has reached $(B=-0.307)$ which is a significant value because the calculated value $(t)$ which is $(4.737)$ is a significant value at $(\mathrm{Sig} .=0.000)$ while the value $\left(\mathrm{R}^{2}\right)$ has reached $(0.094)$ i.e. the hostile work environment explain a proportion of $(9.4 \%)$ of the changes that occur to organizational alienation. As to the remaining $(90.6 \%)$, it refers to other variables not included in the research model. Based on the results attained above, there is a significant effect of hostile work environment on organizational alienation.

It is also evident from table (9) regarding the second regression model that $\left(\mathrm{R}^{2}\right)$ value has reached $(0.216)$ and thus the second regression model has achieved a positive difference in its explanative ability reached (0.122) and this difference is ascribed to the presence of the mediation variable (leader-followers relationship) as being a second variable in the second regression model. By following up the values of effect coefficient (Beta) achieved in the second model, it could be concluded that the leader-followers relationship variable partially mediate the effective relationship between hostile work environment and organizational alienation because the (Beta) coefficient value has decreased for hostile work environment from $(\mathrm{B}=0.307)$ in the first model to $(\mathrm{B}=0.232)$ in the second model.

In order to test the significance of the results effect of the independent variable (hostile work environment) on the adopted variable (organizational alienation) the via mediation variable (leader-followers relationship), (Baron \& Kenny, 1986:1177) recommended using (Sobel) test whereby the significance of the mediation role can be verified.

Sobel test's value can be attained either via a computer application designed by (Preacher \& Loenardelli, 2001) or via a mathematic equation set for this purpose. This test depends when considering its results, on the values of four basic parameters as follows:

1. (a) = unstandardized regression coefficient of the dependent variable effect on the mediation variable.

2. (b) = unstandardized regression coefficient of the mediation variable on the adopted variable (when the independent variable predicts the adopted variable).

3. $(\mathrm{Sa})=$ standard error of $(\mathrm{a})$

4. $(\mathrm{Sb})=$ standard error of $(\mathrm{b})$

significance of (Sobel Test) value depending on (P-value) shown in the test results' table. Table (10) shows the results of this test.

Table 10. Table (Sobel) test's results

\begin{tabular}{cccc}
\hline Regression model & Input & Sobel Test & P-value \\
\hline & $\mathrm{a}=.277$ & & \\
$\mathrm{a}, \mathrm{S}_{\mathrm{a}}=$ HWE-LFR & $\mathrm{b}=.234$ & 2.772 & .005 \\
$\mathrm{~b}, \mathrm{~S}_{\mathrm{b}}=$ HWE-LFR-OA & $\mathrm{Sa}=.088$ & & \\
& $\mathrm{Sb}=.040$ & & \\
\hline
\end{tabular}

From Table (10), it is evident that the (P-value) of the regression model was significant such that emphasizing the significance of mediation role test results of leader-followers relationship between hostile work environment as being a dependent variable and organizational alienation as an adopted variable.

\section{Discussion}

Obviously, the findings of the hypotheses-based tests show that hostile work environment has a great role in leader-followers relationship given that the hostile climate might make the leader-followers relationship weak or passive. This brings us to the fundamental fact that the stimuli that lead to a hostile environment might be ascribed to the management on the one hand and to employees on the other. Therefore the gap between the leader and the followers widens whenever a hostile climate penetrates into the organization's culture and spreads within 
the official lines of authority. This is in line with what has been concluded by (Vance et al, 2004,137) who confirmed that there are sharp psychological reactions to a hostile work environment, which in turn have a passive impact on leader-follower relationship. This leads to high rates of absenteeism and attrition, weak functional performance, greater inclination to quit work, hostile behavior in the organization, low sense of power and personal control among employees, and low expectation of successful performance. It is also obvious that a hostile work environment might make the followers reluctant to execute their leaders' instructions and abide by their orders. This is also confirmed by (Begle, 2015, pp. 1-5) who emphasized that a great number of employees are dissatisfied with their superiors and their jobs as they have been subjected to hostile work environment which is basically based on discrimination and makes work difficult or even unbearable for the employee. This causes a lack of cohesion with his his leader, workmates and his job which in turn lead to administrative and legal problems.

The hypotheses-based test also showed that leader-followers relationship has a great effect on organizational alienation among employees which confirms that the more positive, strong and based on mutual respect and confidence leader-followers relationships are, the less the sense of organizational alienation. This agrees with the view of (Matzdorf \& Sen, 2015, pp. 122-123) who stated that leader-followers relationship assists in improving communication, in order to enable employees fulfill their commitments, increase their confidence, give them independence, enable them to take their own decisions, and hence increase their adherence to work and the organization. It follows that the leader and the followers should have shared values, interests and goals to create a successful work environment and avoid resistance which weakens the relationship between the leader and followers. This also conforms with (Richards \& Hackett, 2012) who concluded that unhealthy forms of the leader and the followers' orientations might appear due to elusion, anxiety and increasing adherence to material interests. These factors have a passive effect on the type of relationship between the two parties and may lead to diminished sense of security and morale among followers in times of stress and uncertainty in particular and would lead in turn to alienation and eventually attrition. The findings also showed that the leader-followers relationship has a mediation role in the relationship between hostile work environment and organizational alienation among employees. This is apparent in two directions. The first is when the leader-followers relationship is positive, strong, and based on communication, cooperation, behaviors of assistance, understanding, and discussions; this kind of leader-follower relations can minimize the effects of the hostile work environment, its details and motives as well as prevent its outbreak at different levels and departments of the organization, and this may lead in turn to lower levels of organizational alienation. The second is when the leader-followers relationship is passive and weak, discourages cooperation and communication, and is based on hostility and distrust. This scenario adds to the effects of hostile work environment and passive behaviors, which in turn increase organizational alienation among employees and weaken their correlation with work as well as the organization.

\section{Conclusions}

Hostile work environment and its manifestations such as lack of functional security, imbalance between work and family lives, bad treatment or harassment at work, passivity, high work stress, dictatorial style of the management, conflicts, and an atmosphere of fear, are crucial factors that undermine organizational performance. The leader-followers relationship is also of special importance at the level of business organizations as it is a significant motivation driver to a great number of positive behaviors and effectively redresses many passive behaviors. Hence, the more positive and based on confidence, trust and sincerity the leader-followers relationship is, the more positive would be the organization's performance. Conversely, a relationship that is hostile, weak and based on material interests leads to passive outcomes that affect the performance of both the leaders and the followers.

It is also obvious that organizational alienation is one of the most detrimental variables that influence the performance of organizations particularly if its causes feelings of disappointment, dissatisfaction, inability to achieve the vocational standards, alienation, and isolation in social relationships with the leaders and workmates. Therefore, the individuals will be unable to meet their social needs which can be translated, within organizational life, into less participation, no organizational identity, applying the minimum skills and knowledge, using behaviors of unhelpfulness, conflict and disagreement in the workplace, minimal involvement in work, lack of commitment to organizational objectives, avoidance of responsibility, lack of independence, and fear of work.

It is therefore clear that hostile work environment has a major effect on leader-followers relationships; in other words, the increasing of hostile behaviors in the work environment will lead, passively, to a weak and hostile relationship between the leader and the followers. Conversely, leader-followers relationship can impact 
organizational alienation in significant ways, which points to the possibility of enhancing and strengthening the leader-followers relationship in order to minimize organizational alienation among employees. It is also obvious that leader-followers relationship could be utilized to mediate between hostile work environment and organizational alienation, especially in cases where prevalence of a hostile work environment and its impact on increasing organizational alienation are confirmed.

This research can help the managers of the general company for cars manufacturing in handling and minimizing the effects of hostile work environment via: developing and activating ethical practices and behaviors based on trust, honesty, sincerity and truthfulness in work; incorporating good citizenship behaviors; and encouraging constant communication between the leaders and followers. The organization's leadership also needs to control hostile behaviors such as cheating, harassment, and offense; diagnose and combat different types of corruption if any; and deal with all kinds of malpractices via strict laws made for the purpose. In addition to these, the present research emphasizes the need for employees to activate self-supervision as it is the best guide for the individual's behavior within the internal environment. Self-supervision contributes greatly towards strengthening positive behavior, supports self-estimate of performance, fosters factors of confidence and morale, and supports commitment among employees. This in turn helps to foster a positive work environment that quietly minimizes employees' isolation and sense of organizational alienation .

As to the theoretical and practical consequences of the research, they could be extracted in the future through utilizing the mediation role of leader-followers relationships in minimizing the effects of hostile work environment and its consequences that weaken performance. However, leader-follower relationships can be utilized effectively to minimize employee alienation only in an environment of organizational integrity. There is also the possibility to utilize the codes of ethical behavior in handling the state of organizational alienation. The positivity of leader-followers relationship serves as an average variable of the relationship between hostile work environment and the conscious exclusion of followers. Hence, integrating these concepts into the scope of the present research will help in establishing a more inclusive framework for analysis in the future.

\section{References}

Adair, R. (2015). Effects of life-threatening illnesses on leader-follower relationships. DeVry University Journal of Scholarly Research, 2(1), 8-15.

Admin. (2012). Judicial supervision of campaign information: A proposal to stop the dangerous erosion of madison's design for actual representation. Hofstra Law Review, 34(1), 229-261.

Aiken, M., \& Hage, J. (1966). Organizational alienation: A comparative analysis. American Sociological Review, 31(4), 497-507.

Allen, B., \& LaFollette, W. (1977). Perceived organizational structure and alienation among management trainees. The Academy of Management Journal, 20(2), 334-341.

Alterman, T., Luckhaupt, S., Dahlhamer, J., Ward, B., \& Calvert, G., (2013). Job insecurity, work family imbalance, and hostile work environment: Prevalence data from the 2010 national health interview survey. American Journal of Ind. Med., 56, 660-669. http://10.1002/ajim.22123

Banai, M. Reisel, W., \& Probst, T. (2014). A managerial and personal control model: predictions of work alienation and organizational commitment in Hungary. Journal of International Management, 10, $375-392$. http://dx.doi.org/10.1016/j.intman.2004.05.002

Begle, B. (2015). Hostile work environment it's not what you may think. Retrieved from http://www.olsonllp. $\mathrm{com} / ?_{\mathrm{s}}=$ HOSTILE+WORK+ENVIRONMENT+It- $\%$ E2\%80\%99s+not+what+you+may+think

Boyd, N., \& Taylor, R. (1998). A developmental approach to the examination of friendship in leader-follower relationships. The Leadership Quarterly, 9(1), 1-25. http://dx.doi.org/10.1016/S1048-9843(98)90040-6

Brannen, M., \& Peterson, M. (2009). Merging without alienating: interventions promoting cross-cultural organizational integration and their limitations. Journal of International Business Studies, 40, 468-489. http://10.1057/jibs.2008.80

Calantone, R., \& Benedetto, C. (1994). How firms organize for successful innovation in hostile environment. The Journal of Technology Transfer, 19(1), 17-26. http://10.1007/BF02373667

Cass, S., M., Levett, L., \& Kovera, M. (2010). The effects of harassment severity and organizational behavior on damage awards in a hostile work environment sexual Harassment Case. Behavioral Sciences and the Law, 28, 303-321. http://10.1002/bs1.886 
Chen, Y., Shang, R., Hou, A., \& Lee, H. (2012). Organizational alienation, organizational support and behavioral intention to adopt information systems. Pacific Asia Conference on Information Systems, 1-16.

Cox, H., \& Wood, J. (1980). Organizational structure and professional alienation: The case of school teachers. Peabody Journal of Education, 58(1), 1-6. http://dx.doi.org/10.1080/01619568009538304

Coyle, P., \& Foti, R. (2014). If you're not with me you're . . ? examining prototypes and cooperation in leaderfollower relationships. Journal of Leadership \& Organizational Studies, September, 22, 1-14. http://10.1177/1548051814550830 jlo.sagepub.com

Davis, R. m., \& C, C. (2013). Decatur area society for Human resource management hostile work environment in all its forms. Retrieved from http://webcache.-googleusercontent.com/search?q=cache:tg0q0773FcIJ: decatur.shrm.org/sites/decatur.shrm.org/files/Hostile\%2520Work\%2520Environment\%2520in\%2520All\%2 520its\%2520Forms\%252010.813\%2520(00108780).pdf +\&cd=1\&hl=en\&ct=clnk\&gl=iq

Dumas, C., \& Sankowsky, D. (1998). Understanding the charismatic leader-follower relationship: Promises and perils. The Journal of Leadership Studies, 5(4), 29-45.

Efraty, D., Sirgy, M., \& Claiborne, C. (1999). The effects of personal alienation on organizational identification: A quality-of-work-life model. Journal of Business and Psychology, 6(1), 57-78. Retrieved from http://www.jstor.org/stable/25092320

Elbanna, S., \& Alhwarai, M. (2012). The Influence of environmental uncertainty and hostility on organization performance (Doctoral thesis). Associate Professor of Strategic Management Faculty of Business \& Economics United Arab Emirates University, UAEU-FBE-Working Paper Series.

EL-sherif, H. (2012). Hostile working environment: Quantitative data analysis. Retrieved from https://www. researchgate.net/publication/269338430_Hostile_Working-_EnvironmentQuantitative_Data_Analysis

Foulds, G. (1964). Organization and hostility in the thematic apperception test stories of schizophrenics. The British Journal of Psychiatry Jan, 110(464), 64-66. http://10.1192/bjp.110.464.64

Gardner, D., Dunham, R., Cumming, L., \& Pierce, J. (1987). Focus of attention at work and leader-follower relationships. Journal of Occupational Behavior, 8(4), 277-294. http://www.jstor.org/stable/3000255

Garzia, D. (2011). The personalization of politics in western democracies: Causes and consequences on leaderfollower relationships. Leadership Quarterly, 22, 697-709. http://dx.doi.org/10.1016/j.leaqua.2011.05.010

Grayson, D., \& Speckhart, R. (2006). The leader-follower relationship: Practitioner observations. Leadership Advance Online, 6(Winter), 1-6.

Hinojosa, A. McCauley, K. Seng, B., \& Gardner, W. (2014). Leader and follower attachment styles: Implications for authentic leader-follower relationships. The Leadership Quarterly, 25(3), 595-610. http://dx.doi.org/10.1016/j.leaqua.2013.12.002

Hutchinson, M., \& Jackson, D. (2103). Hostile clinician behaviors in the nursing work environment and implications for patient care: a mixed-methods systematic review. Hutchinson and Jackson BMC Nursing, 4, 1-12. http://10.1186/1472-6955-12-25

JR, D. (2001). Play nice or pay up: Appeals courts allow ADA hostile work environment claims split on awards. ABA Journal, 87(8), 22.

Judge, T. Scott, B., \& Ilies, R. (2006). "Hostility, job attitudes, and workplace deviance: test of a multi-level model. J. of Applied Psychology, 91(1), 126-138. http://psycnet.apa.org/doi/10.1037/0021-9010.91.1.126

Kakabadse, A. (1986). Organizational alienation and job climate a comparative study of structural conditions and psychological adjustment. Small group behavior, 17(4), 458-4711. http://eric.ed.gov/?id=EJ348826

Kark, R. (2011). Workplace Intimacy in leader-follower relationships. Retrieved from https://www.academia.edu/1134356/Workplace_Intimacy_in_Leader_Follower_Relationships

Korkmaz, O., \& Aydemir, S. (2015). A research for the determination of the relationship between organizational conflict management and organizational alienation. I. Review of Management and Marketing, 5(4), 230-241

Lim, J., \& Chidambaram, L. (2011). A longitudinal comparison of leader-follower relationships between high and low performing self-managed work teams in virtual settings. System Sciences (HICSS), 2011. 44th Hawaii International Conference on, pp. 1-10. http://10.1109/HICSS.2011.15

Malakyan, P. (2014). Followership in leadership studies: A case of leader-follower trade approach. Journal of Leadership Studies, 7(4), 6-22. http://10.1002/jls.21306 
Mann, S., \& Goodman, D. (2008). Sexual harassment isn't always the issue appellate courts and other factors that contribute to a hostile work environment. Review of Public Personnel Administration, 28(2), 190-196. http://10.1177/0734371X07310481

Martinez, A., Kane, R., Ferris, G., \& Brooks, C. (2012). Power in leader-follower work relationships. Journal of Leadership \& Organizational Studies, 19(2), 142-151. http://10.1177/1548051811433358

Matzdorf, F., \& Sen, R. (2015). Demanding followers, empowered leaders: Dance as an "Embodied Metaphor" for leader-follower-ship. Organizational Aesthetics, 5(1), 114-130. http://digitalcommons.wpi.edu/oa/vol5/iss1/7

Mendoza, M., \& Lara, P. (2007). The impact of work alienation on organizational citizenship behavior in the canary islands. I. J. of Organizational Analysis, 15(1), 56-76. http://10.1108/19348830710860156

Neagle, C. (2001). An analysis of the applicability of hostile work environment liability to the ADA. Journal of Labor and Employment, 2(3), 715-740.

Nienaber, A., Hofeditz, \& M. Romeike, P. (2015). Vulnerability and trust in leader-follower relationships. Personnel Review, 44(4), 567-591. http://dx.doi.org/10.1108/PR-09-2013-0162

Oyarce, C. (2009). Environmental hostility, individual learning, and intrapreneurship as predictors of organizational learning: A study applied to two selected mining companies in chile (Doctor of Philosophy, Submitted to the Office of Graduate Studies of Texas A\&M University, pp. 1- 203).

Payne, P. (2015). The leader-follower relationship and how it relates to employees' perception of their own leadership (Doctor Thesis). Submitted to the Faculty of Olivet Nazarene University, School of Graduate and Continuing Studies, pp. 1-88.

Pelit, E., Dincer, F., \& K1lic, I. (2015). The effect of nepotism on organizational silence, alienation and commitment: A study on hotel employees in turkey. Journal of Management Research, 7(4), 82-110. http://dx.doi.org/10.5296/jmr.v7i4.7806

Pelletier, K. (2012). Perceptions of and reactions to leader toxicity: Do leader-follower relationships and identification with victim matter? The Leadership Quarterly, 23(3), 412-424. http://dx.doi.org/10.1016/j.leaqua.2011.09.011

Podsakoff, P., Williams, L., \& Todor, W. (1986). Effects of organizational formalization on alienation among professionals and nonprofessionals. The Academy of Management J., 29(4), 820-831. http://10.2307/255948

Post, J. (1986). Narcissism and the charismatic leader-follower relationship. Political Psychology, 7(4), 675-688. http://10.2307/3791208

Psaila, P., \& Birch, K. (2015). Managing workplace hostility: A proactive approach to positive working environments. Retrieved from http://webcache.googleusercontent.--com/search?q=cache:vaSZF12dgM4J:w ww.psypotential.com/wpcontent/uploads/2015/06/Managing-Workplace-Hostility-a-proactive-approach-topositive-working-environments.pdf $+\& \mathrm{~cd}=1 \& \mathrm{hl}=\mathrm{en} \& \mathrm{ct}=\mathrm{clnk} \& \mathrm{gl}=\mathrm{iq}$

Rajaeepour, S., Azizollah, A., Mahmoud, Z., \& Solmaz, S. (2012). Relationship between organizational structure and organizational alienation. Interdisciplinary J. of Contemporary Research in Business, 3(12), 188-196.

Ramaswami, S. Agarwal, S., \& Bhargava, M. (1993). Work alienation of marketing employees: Influence of task, supervisory, and organizational structure factors. Journal of the Academy of Marketing Science, 21(3), 179-193. http://10.1177/0092070393213002

Rauf, F. (2015). Twenty first century human resource management practices: Why does organizational justice matter? An examination of effect of perception of organizational injustice on work alienation and organizational citizenship behavior. I. J. of Engineering Research and Management, 2(8), 94-100.

Rovai, A., \& Wighting, M. (2005). Feelings of alienation and community among higher education students in a virtual classroom. Internet and Higher Education, 8, 97-110. http://dx.doi.org/10.1016/j.iheduc.2005.03.001

Rubin, J. (1995). The development of hostile environment sexual harassment law: Struggling to define actionable conduct. Retrieved from https://www.researchgate.net/publication/27653528_The_Development_of_Hostil e_Environment_Sexual_Harassment_Law_Struggling_to_Define_Actionable_Conduct?ev=srch_pub\&_sg= fÜ8Kdjza4Nf87MCt7wE6RLadjGZN̄AaSVDzWf9igPHsU7s5wnN_MDb6FmdbN-mb0w.t_eYc7KxWjdQ XqkXwmgb27SV_nx4R-vVuwMY3y2Ey1RWLMJDu6UmtEERGM_8j739.QWsgZe3PWneTf5W6gaf50t NvVkVrT2unOizhVieZu1Khi_ZOUO1efBnp96-4modq 
Sarros, J.Tanewski, G.Winter, R.Santora, J., \& Densten, I. (2002). Work alienation and organizational leadership. British Journal of Management, 13, 285-304. http://10.1111/1467-8551.00247

Savolainen, T. (2009). Trust development in leader-follower relationships. Retrieved from https://www.academia.edu/419427/Trust_Development_In_Leader-Follower_Relationships

Shantz, A. Alfes, K. Bailey, C., \& Soane, E. (2015). Drivers and outcomes of work alienation a concept. Journal of Management Inquiry, 1-12. http://10.1177/1056492615573325

Shehada, M., \& Khafaje, N. (2015). The manifestation of organizational alienation of employees and its impact on work conditions. International Journal of Business and Social Science, 6(2), 82-86.

Sirin, H., \& Sirin, E. (2013). Research on the organizational commitment of the instructors in terms of job satisfaction, and organizational alienation: school of physical education and sports sample. International Journal of Academic Research, 5(3), 176-183.

Stephenson, T. (1959). The Leader-Follower Relationship. The Sociological Review, 7(2), 179-195. http://10.1111/j.1467-954X.1959.tb01027.x

Sulu, S., Ceylan, A., \& Kaynak, R. (2010). Work alienation as a mediator of the relationship between organizational injustice and organizational commitment: Implications for healthcare professionals, International Journal of Business and Management, 5(8), 27-38. http://dx.doi.org/10.5539/ijbm.v5n8p27

Thomas, C., \& Zingraff, M. (1976). Organizational structure as a determinant of prisonization: An analysis of the consequences of alienation. The Pacific Sociological Review, 19(1), 98-116. http://10.2307/1388745

Thomas, G. Martin, R. Epitropaki, O. Guillaume, Y., \& Lee, A. (2013). Social cognition in leader-follower relationships: Applying insights from relationship science to understanding relationship-based approaches to leadership. Journal of Organizational Behavior, 34, 63-81. http://10.1002/job.1889

Tummers, L., \& Dulk, L. (2013). The effects of work alienation on organizational commitment, work effort and work-to-family enrichment. Journal of Nursing Management, 21(6), 850-859. http://10.1111/jonm.12159

Valadbigi, A., \& Ghobadi, S. (2012). The study of the elements of work alienation (A case study of the orumiyeh withe cement factory, western azerbaijan province, Iran). International Journal of Sustainable Development, 4(9), 71-84. http://dx.doi.org/10.5539/ass.v7n6p206

Valikhani, M., \& Soltani, E. (2015). Investigating the effect of job alienation on the organizational citizenship behavior (branches of sepah bank in shahreza and dehaghan as case study). International Journal of Academic Research in Business and Social Sciences, 5(1), 277-286. http://10.6007/IJARBSS/v5-i1/1427

Vance, C. Ensher, E. Hendricks, F., \& Harris, C. (2004). Gender-based vicarious sensitivity to disempowering behavior in organizations: Exploring an expanded concept of hostile working environment. Employee Responsibilities and Rights Journal, 16(3), 135-147. http://10.1023/B:ERRJ.0000038649.75806.28

Wagner \& Lip. (2005). What is a hostile work environment? Legal Update, 8(1). Retrieved from http://webcache.googleusercontent.com/search?q=cache:viN9euIdguoJ:www.hwelaw.com/0305.pdf $+\& c d=1$ $\& \mathrm{hl}=\mathrm{en} \& \mathrm{ct}=\mathrm{clnk} \& \mathrm{gl}=\mathrm{iq}$

Wiener, R. Watts, B. Goldkamp, K., \& Gasper, C. (1995). Social analytic investigation of hostile work environments a test of the reasonable woman standard. Law and Human Behavior, 19(3), 263-281.

Winkler, I. (2011). Non-standard employment and leadership research: On consequences for conceptualizing the leader-follower relationship. Leadership, 7(4), 499-511. http://10.1177/1742715011417496

Wisse, B., \& Rietzschel, E. (2014). Humor in leader-follower relationships: Humor styles, similarity and relationship quality, Humor, 27(2), 249-269. https://doi.org/10.1515/humor-2014-0017

Yorulmaz, y., Altinkurt, y., \& Yilmaz, K. (2015). The relationship between teachers' occupational professionalism and organizational alienation. Educational Process: International Journal, 4(1-2), 31-44. http://10.12973/edupij.2015.412.3

\section{Copyrights}

Copyright for this article is retained by the author(s), with first publication rights granted to the journal.

This is an open-access article distributed under the terms and conditions of the Creative Commons Attribution license (http://creativecommons.org/licenses/by/4.0/). 